\title{
Study of complementary feeding practices in mothers of infants aged 6- 12 months
}

\author{
Patil $\mathbf{N}^{1}$, Bawa $\mathbf{R}^{2}$, Patil $\mathbf{R R}^{3}$ \\ ${ }^{1}$ Dr. Nivedita Patil, Associate Professor, Department of Pediatrics, ${ }^{2}$ Dr. Rajwinder Bawa, Resident, Department of \\ Pediatrics, ${ }^{3}$ Dr. Rahul Ravso Patil, Lecturer, Department of Pediatrics. All are affiliated with D.Y. Patil University, \\ Kolhapur, Maharashtra, India
}

Address for correspondence: Dr. Rajwinder Bawa, Email: rajwinderbawa26@gmail.com

\begin{abstract}
Introduction: Timely introduction of appropriate and adequate complementary feeds to infants, at the age of 6-9 months is important for the optimal growth of the child. It is essential for child's mental growth, to prevent under-nutrition and anemia. NFHS-3 data reveals only 55.8\% children being introduced to complementary feeds along with continued breastfeeding at age of 6-9 months. Our study was taken to know the profile of various locally prevalent complementary foods, various food beliefs and factors influencing introduction of complementary feeding to infants aged 6-12 months. Materials and Methods: Study was carried out in D.Y. Patil Hospital, where, mothers of 120 infants fulfilling the inclusion criteria were interviewed and data regarding the socio-demographic factors, maternal factors and feeding practices was collected in a structured format. The data was then analyzed using various statistical methods and SPSS software. Results: The study revealed that incidence of initiating complementary feeding at 6 months is $31.6 \%$. Only $14.28 \%$ infants of working mothers received right consistency of complementary feeds. The most common reason for early initiation of complementary feeding was mothers being working while for delay was that baby vomits or gags the complementary food. Animal milk and milk based preparations were commonly used complementary foods. Conclusion: There is lack of knowledge regarding the ideal complementary feeding practices amongst the mothers. Health workers should educate the mothers regarding continuation of breastfeeding and appropriate timing of introduction of complementary feeds. Mothers need to be taught about the adequate frequency, quantity and appropriate consistency of complementary feeds.
\end{abstract}

Key words: Complementary Feeding, Exclusive Breastfeeding, Infant Feeding, Nutrition

\section{Introduction}

WHO and UNICEF's global recommendations for optimal infant feeding as set out in the Global Strategy are [1] Exclusive breastfeeding for 6 months (180 days) and nutritionally adequate and safe complementary feeding starting from the age of 6 months with continued breastfeeding up to 2 years of age or beyond. Complementary feeding means giving other foods in addition to breast milk. India has very high rates of under-nutrition in children with a prevalence of stunting among under five being $48 \%$, wasting $20 \%$ and underweight $43 \%$, [2] it is the highest in the world. The early ages are affected more which makes the process irreversible. Introduction of appropriate and adequate complementary food at 6-9 month of age, [3] is necessary to prevent under-

Manuscript received: $25^{\text {th }}$ Feb 2016

Reviewed: $8^{\text {th }}$ March 2016

Author Corrected; $18^{\text {th }}$ March 2016

Accepted for Publication: $31^{\text {st }}$ March 2016 nutrition and improve child survival, [4, 1] preventing an additional $6 \%$ child deaths. [5] It is viewed as a major contributor to reduce nutritional anemia [6]. Latest National Health Survey has revealed that in India introduction of complementary feeding along with continued breastfeeding in 6-9 month age is only $55.8 \%$ [7]. Thereby we undertook a study to know the profile of various locally prevalent complementary foods, various food beliefs and factors influencing introduction of complementary feeding to infants of age group 6-12 months.

\section{Materials \& Methods}

This was a prospective, hospital based study, conducted at D.Y. Patil Hospital, Kolhapur. After approval from ethical committee of hospital and informed consent taken from the mothers, data was collected from every 
consecutive mother of infants fulfilling the inclusion criteria. All the healthy babies of age 6-12 months visiting the hospital OPD and Immunization clinics were included in the study. Babies with congenital defects like cleft lip/ cleft palate and infants suffering from chronic diseases were excluded from the study. All mothers of infants in age group 6-12 months visiting OPD and Immunization clinics were interviewed and information in a structured format was collected. Questionnaire comprised of sociodemographic factors and maternal factors in relation to infant feeding. The collected data was then analyzed using various statistical methods like chi square test, multiple logistic regression and SPSS version 11.5.

\section{Results}

Amongst 120 infants, the mean age was 8.5 months (SD +/- 1.6months). The observed male to female ratio was $1.35: 1$. Majority of the infants $(70.9 \%)$ had weight between 8 to $9 \mathrm{~kg}$, the mean weight of the group was $7.9 \mathrm{~kg}$ (SD $+/-0.82 \mathrm{~kg})$. 31 cases $(25.83 \%)$ were found to be underweight (as per WHO criteria). There was no apparent sex difference found in underweight infants. Only $56.7 \%$ cases had exclusive breastfeeding up to 6 months.

38 infants $(31.6 \%)$ were initiated complementary feeding at 6months of age, 29 infants $(24.1 \%)$ were weaned prematurely before the age of 6 months. In our study, no statistical significant relation was found in the residential area, family income and time of initiation of complementary feeding. Other maternal factors like maternal education, maternal occupation, birth order of the child were also not related to time of introduction of complementary foods to the infants.

The most common reason found for early initiation of complementary feeding (Table I) was mothers being working, while, for delay in initiation of complementary feeding was that baby did not accept Complementary food (vomits or gags).

Table I: Reason for initiating complementary feeding.

\begin{tabular}{|l|l|l|}
\hline Reason for initiation CF & Frequency & \% of cases \\
\hline EARLY & & \\
Breast milk not sufficient & 6 & 5.0 \\
Hunger not satisfied & 7 & 5.8 \\
Lack of knowledge & 4 & 3.3 \\
Working mother & 8 & 6.7 \\
Family pressure & 7 & 5.8 \\
LATE & 5 & \\
Breast milk sufficient for the baby & 7 & 4.2 \\
Not accepting CF & 1 & 5.8 \\
Cost effective & & 0.8 \\
CF Started at appropriate time & 75 & 62.5 \\
\hline Total & $\mathbf{1 2 0}$ & $\mathbf{1 0 0 . 0}$ \\
\hline
\end{tabular}

In our study, 108 infants out of $120(90 \%)$ were given complementary feeds in appropriate frequency. No association was found between the maternal and the socio-demographic factors studied and right frequency of complementary feeds given to the infants.

Out of 120 cases studied, 77 cases $(64.1 \%)$ were found to be offering thin in consistency complementary foods. Of all the factors studied it was found that there was statistical significance in maternal occupation and right consistency of complementary foods (Table II).

Only $14.28 \%$ infants of working mothers received right consistency food while $36.36 \%$ homemaker mothers gave right consistency food to their infants. 
Table II: Multivariate logistic regression for finding the independent determinants of right consistency of CF [Multiple Logistic Regression Analysis]

\begin{tabular}{|c|c|c|c|c|c|c|}
\hline \multicolumn{2}{|c|}{ Maternal factors } & \multicolumn{2}{|c|}{ Right consistency of $\mathrm{CF}$} & \multicolumn{2}{|c|}{$\begin{array}{l}\text { Multivariate Odds } \\
\text { Ratios (OR) }\end{array}$} & \multirow[b]{2}{*}{ P-value } \\
\hline & & Right (n=39) & $\begin{array}{l}\text { Thin/Thick } \\
(n=81)\end{array}$ & OR & $\begin{array}{l}95 \% \text { CI of } \\
\text { OR }\end{array}$ & \\
\hline Residence & $\begin{array}{l}\text { Urban }(n=52) \\
\text { Urban slums }(n=48) \\
\text { Rural }(n=20)\end{array}$ & $\begin{array}{l}14(26.9) \\
20(41.7) \\
5(25.0)\end{array}$ & $\begin{array}{l}38(73.1) \\
28(58.3) \\
15(75.0)\end{array}$ & $\begin{array}{l}1.00 \\
0.76 \\
1.19\end{array}$ & $\begin{array}{l}-- \\
0.64-1.07 \\
0.77-1.91\end{array}$ & $\begin{array}{l}-- \\
0.667^{\mathrm{NS}} \\
0.245^{\mathrm{NS}}\end{array}$ \\
\hline $\begin{array}{l}\text { Maternal } \\
\text { education }\end{array}$ & $\begin{array}{l}\text { Illiterate }(n=5) \\
\text { Up to intermediate }(n=111) \\
\text { Graduate }(n=4)\end{array}$ & $\begin{array}{l}1(20.0) \\
38(34.2) \\
0\end{array}$ & $\begin{array}{l}4(80.0) \\
73(65.8) \\
4(100.0)\end{array}$ & $\begin{array}{l}0.74 \\
0.87 \\
1.00\end{array}$ & $\begin{array}{l}0.55-1.13 \\
0.60-1.24 \\
--\end{array}$ & $\begin{array}{l}0.413^{\mathrm{NS}} \\
0.399^{\mathrm{NS}} \\
--\end{array}$ \\
\hline Occupation & $\begin{array}{l}\text { Homemaker }(n=99) \\
\text { Service }(n=21)\end{array}$ & $\begin{array}{l}36(36.4) \\
3(14.3)\end{array}$ & $\begin{array}{l}63(63.6) \\
18(85.7)\end{array}$ & $\begin{array}{l}1.00 \\
1.64\end{array}$ & $\begin{array}{l}-- \\
1.08-2.18\end{array}$ & $\begin{array}{ll}-- \\
0.048^{*}\end{array}$ \\
\hline Income & $\begin{array}{l}<10000 \operatorname{Rs}(\mathrm{n}=51) \\
>10000 \operatorname{Rs}(\mathrm{n}=69)\end{array}$ & $\begin{array}{l}13(25.5) \\
26(37.7)\end{array}$ & $\begin{array}{l}38(74.5) \\
43(62.3)\end{array}$ & $\begin{array}{l}1.22 \\
1.00\end{array}$ & $\begin{array}{l}0.87-1.94 \\
--\end{array}$ & $\begin{array}{l}0.335^{\mathrm{NS}} \\
--\end{array}$ \\
\hline Birth order & $\begin{array}{l}1(\mathrm{n}=52) \\
2(\mathrm{n}=59) \\
3(\mathrm{n}=9)\end{array}$ & $\begin{array}{l}18(34.6) \\
18(34.6) \\
3(33.3)\end{array}$ & $\begin{array}{l}34(65.4) \\
41(69.5) \\
6(66.7)\end{array}$ & $\begin{array}{l}1.00 \\
1.10 \\
1.08\end{array}$ & $\begin{array}{l}-- \\
0.83-1.43 \\
0.79-1.38\end{array}$ & $\begin{array}{l}-- \\
0.408^{\mathrm{NS}} \\
0.557^{\mathrm{NS}}\end{array}$ \\
\hline
\end{tabular}

$[$ Odds Ratio $=1:$ Reference Category]. $*$ P-value $<0.05$ (Statistically significant), NS: Statistically Non-Significant.

This study shows that maternal occupation was significantly associated with right consistency of complementary foods ( $\mathrm{p}$ value 0.048 ) while residential area, maternal education, family income and birth order had no association with the complementary food consistency.

Varieties of foods were used for complementary feeding (Figure I). The most commonly used complementary food was milk and milk based preparations $(45.8 \%)$. The percentage of infants given only milk as complementary food was $20.83 \%$. Many mothers gave more than one food.

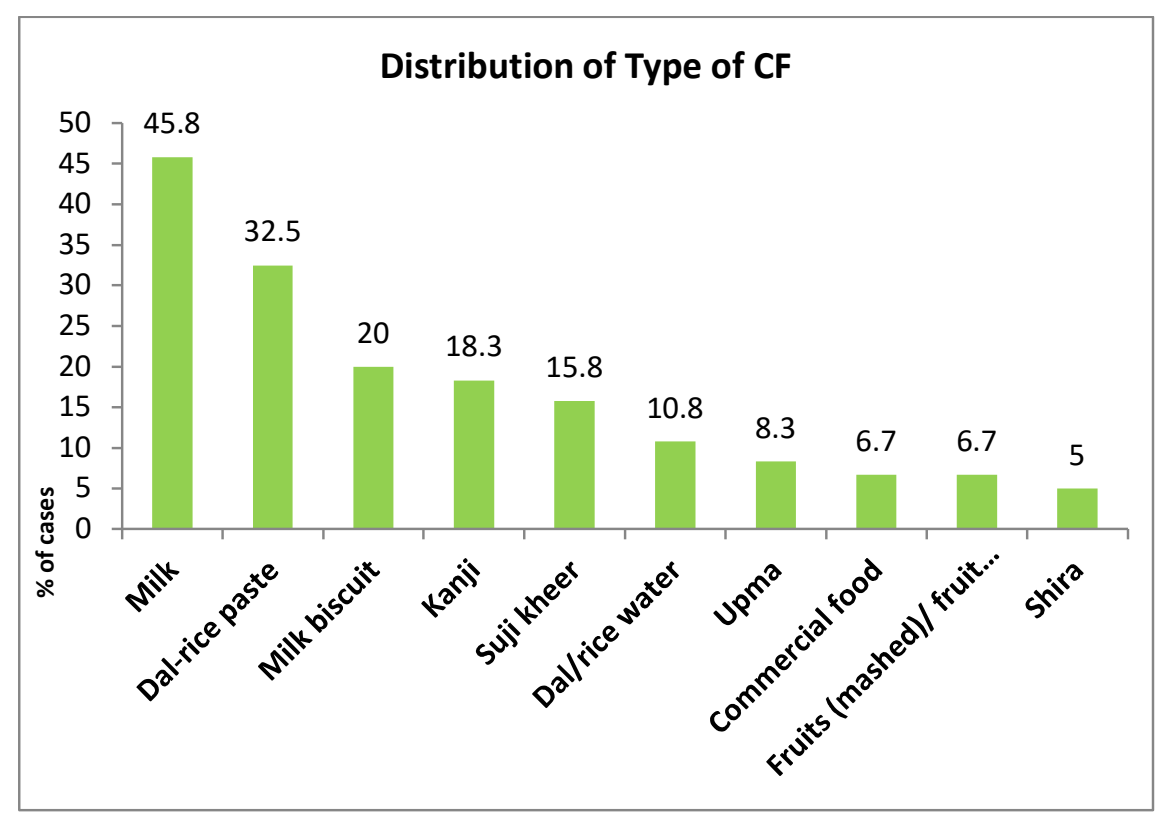

Figure I: Distribution of type of complementary foods 


\section{Discussion}

This hospital based study showed 88 out of 120 infants $(73.3 \%)$ were started complementary feeding between the ages of 6 to 9 months. This was higher than the state NFHS-3 data [7] which documented $47.8 \%$ children aged 6-9months receiving solid or semi-solid food and breast milk. NFHS-3 data for India showed 55.8\% of children were initiated with complementary foods within $6-9$ months. BPNI study reported $48.3 \%$ mothers practiced complementary feeding during 6-9months. A prospective interview study of 200 parents by Aggarwal et al [8] showed that only $17.5 \%$ of mothers had started complementary feeding at recommended time. A study from Delhi indicated that premature weaning was observed only in $5.5 \%$ children, which is lesser than the present study. [9] Our study we did not find statistically significant relation between timely initiation of complementary feeding and various socio-demographic and maternal factors. In our study, the most common reason found for early initiation of complementary feeding was mothers being working. Caetano et al [10] stated that the mothers gave most common reason for early interruption of breastfeeding as little production of milk and child's refusal to be breastfed. A Semahegn et al [11] found various reasons for early initiation of complementary feeding (4-6 months of age). The reasons given were lack of knowledge (47.2\%), inadequate breast milk production (30.6\%). In our study, 108 infants out of $120(90 \%)$ had appropriate frequency of complementary feeds. Out of all the sociodemographic factors of mothers studied, no association was found between area of residence, family income, maternal education, maternal occupation, birth order and right frequency of complementary feeds given to the infants. $64.1 \%$ infants were found to be taking thin in consistency complementary foods. Out of all the studied factors it was found that there was statistically significant relationship between maternal occupation and right consistency of complementary foods. It could be due to the fact that mothers are away for work and other family members taking caring of the child do not have proper knowledge about the consistency and type of food to be given. These results are comparable with the study done by Shivani Lodha and Vandana Bhat [12] where, 59\% mothers were giving thin consistency foods whereas $41 \%$ mothers were giving appropriate consistency of feeds. Study by A. Aggarwal et al., 2008 , it was found that $62 \%$ mothers were giving thin consistency feeds. [8] It is essential to introduce varied textures throughout complementary feeding period. Under normal scenario, the mother tends to give thin or soft, completely mashed foods for a longer period. This might not satisfy baby's urge to chew with the development of teeth and preparation for textured family diet could be difficult. It is essential to advise mothers to differentiate the texture through the preparation and cooking methods. A soft to coarser to bigger bite texture will be a positive approach towards developing the baby for acceptance of family food. [13] A study done in Nepal found $50.91 \%$ mothers fed their children appropriate complementary foods by consistency which is higher as compared to our study. Sethi $\mathrm{V}$ et al showed $30 \%$ mothers were giving right consistency foods which are comparable to our results of $32.5 \%$. [14]

Various misbelieves and misconceptions exist amongst mothers regarding preferences for type of food used as complementary food. Like Shivani Lodha et al and A Semahegn et al, our study also reports milk and milk based preparations being commonly used as complementary food $[11,12]$. This preference can be attributed to the fact that most of the mothers believe that milk is a complete food. Easy availability of animal milk and good acceptance by infants favors its use as complementary food. Milk is used as base for preparing various semi-solid cereal based complementary foods. Only $6.7 \%$ of infants were given mashed fruits because mothers considered fruits as "cold" food which may result in chest congestion.

\section{Conclusion}

Incidence of starting complementary feeding at 6 months is low i.e. $31.6 \%$. Socio-demographic parameters like residential area, maternal education, family income and birth order has no association with timely initiation of complementary feeding, frequency and consistency of complementary feeds. However, maternal occupation is associated with right consistency of complementary feeds. The most common reason for early initiation of complementary feeding is mothers being working, while, for delay in initiation of complementary feeding is that baby does not accept complementary food (vomits or gags). The most commonly used complementary food is animal milk and milk based preparations. The reason being, easy availability and mother's belief that milk is a complete food. Mothers lack knowledge about homemade, healthy complementary foods that can be easily prepared and given to the infants. The breach in the ideal complementary feeding practices and what mothers practice is due to lack of knowledge. Mothers need to be educated about proper complementary 
feeding practices. Whenever there is opportunity for health care workers i.e. during delivery, postnatal period, immunization and OPD visits to pediatricians, mothers should be educated.

Acknowledgment: Heartfelt thanks to all the mothers who participated in the study enthusiastically. Thanks to

\section{References}

1. WHO/UNICEF. Global strategy for infant and young child feeding. Geneva: World Health Organization; 2003.

2.UNICEF. The state of the world's children. Adolescence: Children with disabilities. 2013. [Last retrieved on 2013 Aug 10]. Available from: http://www.unicef.org/sowc2011/

3. Northstone K, Emmett P, Nethersole F; ALSPAC Study Team. Avon Longitudinal Study of Pregnancy and Childhood. The effect of age of introduction to lumpy solids on foods eaten and reported feeding difficulties at 6 and 15 months. J Hum Nutr Diet. 2001 Feb;14(1):43-54. doi: 10.1046/j.1365277x.2001.00264.x

4. Black RE, Morris SS, Jennifer B. Where and why are 10 million children dying every year? Lancet 2003; 361, No. 9376: 2226-2234.doi: http://dx.doi.org/10.1016/S0140-6736(03)13779-8.

5. Jones G, Steketee RW, Black RE, Bhutta ZA, Morris SS; Bellagio Child Survival Study Group. How many child deaths can we prevent this year? Lancet. 2003 Jul 5;362(9377):65-71.

6. Bhutta ZA, Ahmed T, Black RE, Cousens S, Dewey K, Giugliani E, Haider BA, Kirkwood B, Morris SS, Sachdev HP, Shekar M; Maternal and Child Undernutrition Study Group. What works? Interventions for maternal and child undernutrition and survival. Lancet. 2008 Feb 2;371(9610):417-40. doi: 10.1016/S0140-6736(07)61693-6. the members of Department of Pediatrics, D.Y. Patil Hospital, Kolhapur for lending their helping hand to complete this study. A special thanks to our statistician.

\author{
Funding: None \\ Conflicts of Interest: None
}

7. National Family Health Survey - 3. International Institute for Population Sciences. Available at: http://www.nfhsindia.org/nfhs3_national_report.html

8. Aggarwal A, Verma S, Faridi M; Dayachand. Complementary feeding--reasons for inappropriateness in timing, quantity and consistency. Indian $\mathrm{J}$ Pediatr. 2008 Jan;75(1):49-53.

9. Kumar D, Goel NK, Mittal PC, Misra P. Influence of infant-feeding practices on nutritional status of underfive children. Indian J Pediatr. 2006 May;73(5):417-21.

10. Caetano MC, Ortiz TT, Silva SG, Souza FI, Sarni RO. Complementary feeding: inappropriate practices in infants. J Pediatr (Rio J). 2010 May-Jun;86(3):196201.doi:10.2223/JPED.1994. Epub 2010 Apr 16.

11.Semahegn, Agumasie, Gezahegn Tesfaye, and Alemayehu Bogale. "Complementary Feeding Practice of Mothers and Associated Factors in Hiwot Fana Specialized Hospital, Eastern Ethiopia." The Pan African Medical Journal18 (2014): 143. PMC. Web. 27 Nov. 2015.doi: 10.11604/pamj.2014.18.143.3496

12. Shivani Lodha and Vandana Bharti. Assessment of complementary feeding practices and misconceptions regarding foods in young mothers. IJFANS Vol.2, Iss.3, Jul-Sep 2013. Available at http:/www.ijfans.com/currentissue.html

13. Giugliani R.J Elsa, Victora Cesar Gomes. Complementary feeding. Jornal de Pediatria 2000; Supl.3; S253-263.

14. Sethi V, Kashyap S, Seth V. Effect of nutrition education of mothers on infant feeding practices. Indian J Pediatr. 2003Jun;70(6):463-6.

\section{How to cite this article?}

Patil N, Bawa R, Patil RR, Study of complementary feeding practices in mothers of infants aged 6-12 months. Int J Pediatr Res 2016;3(3):183-187. doi:10.17511/ijpr.2016.i03.08. 